Rey Villaronga, Gonzalo José.

Artista visual e investigador. Universidade de Vigo, Facultade de Belas Artes. Estudiante de Doctorado, Departamento de Pintura.

\title{
El borrado como estrategia de producción artística.
}

\section{Erased as an artistic production strategy.}

\author{
TIPO DE TRABAJO:
}

Comunicación.

PALABRAS CLAVE:

Negación, pintura, borrado, palabra.

KEY WORDS:

Denial, painting, erasure, word.

RESUMEN.

Con el análisis de la performance "Viena says..." del artista alemán Nasan Tur pretendemos demostrar como el borrado no sólo es una práctica a la que se llega a través de la sustracción, sino también a través de la adicción. Y cómo esta práctica tiene mucho que ver con la sobreabundancia de las imágenes y la pérdida de la identidad. Este análisis forma parte de un trabajo más extenso que desarrollamos sobre las prácticas antivisuales en la contemporaneidad.

\section{ABSTRACT.}

With the analysis of the performance "Vienna says ..." by the German artist Nasan Tur we try to demonstrate how erasure is not only a practice that is reached through subtraction, but also through addiction. And how this practice has much to do with the over abundance of images and the loss of identity. This analysis is part of a more extensive work that we develop on the anti-traditional practices in contemporaneity.

\section{CONTENIDO.}

\section{Introducción}

Nasan Tur (Alemania,1974) en su trabajo parte del entorno urbano, la calle, la plaza, el bar, una mezquita, una escalera, un aeropuerto, es decir, donde la gente se cruza temporalmente, donde los caminos y las ideas heterogéneas se enfrentan. Sus intervenciones tienen como objetivo romper con normalidad e investigar las situaciones donde se infringen los acuerdos.

Es un artista que trabaja con su propio cuerpo preferiblemente a través de las acciones o las video-performances con las que reflexiona sobre las condiciones sociales del individuo en la sociedad. Y para ello recurre con frecuencia a la exploración de las ideologías políticas, los mensajes subliminales y los símbolos del poder en la comunicación que están presentes en el paisaje urbano.

Estas dos ideas, la del mensaje subliminal y la del proceso de comunicación en el contexto de la ciudad, creemos nos pueden servir para profundizar un poco más en nuestra línea de investigación que llebamos a cabo sobre las poéticas antivisuales. Siguiendo la idea de que en estos procesos de antivisualidad la obra del artista puede sufrir el proceso de [...] "ocultación del objeto visible, desmaterialización como desolidificación de la obra y desaparición con todo tipo de trabajo sobre la huella". (Hernández- Navarro, 
2016:18) podemos reflexionar como la obra Viena says a través de un borrado muy particular se desmaterializa hasta su desaparición. Y lo hace con un proceso de superposición consciente que se pone en relación con la aptidud que adoptan ciertos artistas a la hora de utilizar ciertas estrategias de ocultación para la representación de la realidad (Meana Martínez, 2011).

La obra de Nasan Tur que a continuación analizaremos creemos responde a esta estética de la negación. La performance realizada en el año 2012, formaba parte de un conjunto de propuestas que reflexionaban a través del graffiti sobre la pérdida de comunicación en la sociedad occidental.

Materializa de alguna forma el descrédito en la sociedad de la imagen y la publicidad y plantea una reflexión a través de la ironía y la desaparición precisamente de cualquier forma de rebeldía salida de los suburbios y del lenguaje de la calle.

Independientemente de esta reflexion central de denuncia nos gustaría llamar la atención como de un proceso repetido de superposición de imágenes se puede llegar al concepto de borrado y concluir como este mismo proceso se podría dar a la inversa. Sería aventurado plantear cualquier planteamiento en el arte sobre este concepto sin partir del Erased de De Kooning de Robert Rauschenberg (1953), sin embargo, y amparándonos en la primera definición que da la Real Academia Española de la lengua para la palabra, acción de "hacer desaparecer por cualquier medio lo representado" creemos que es perfectamente posible.

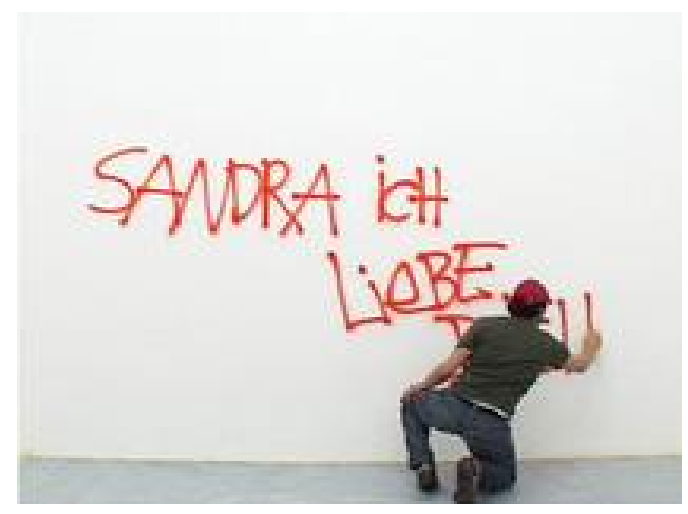

Figura 2. Momento de la performance Viena says... perteneciente a la serie The city says... realizada por Nasan Tur, en el año 2009.

\section{Primer acto. Denuncia.}

En este trabajo el artista explora la interacción del lenguaje y los símbolos en el espacio público. La obra de la imagen superior forma parte de la serie de un trabajo titulado The city says... En esta obra reúne más de cien frases pintadas en graffiti que toma de las paredes de las casas de la ciudad y las pinta con aerosol de nuevo en una pared interior de su estudio o de la galería. Son frases de la cotidianeidad de la calle como un Te quiero, No hay respeto, Su pluma es un arma, Lucha contra el poder, Libertad para...



Figura 3. Momento de la performance Viena says... perteneciente a la serie The city says... realizada por Nasan Tur, en el año 2009. 


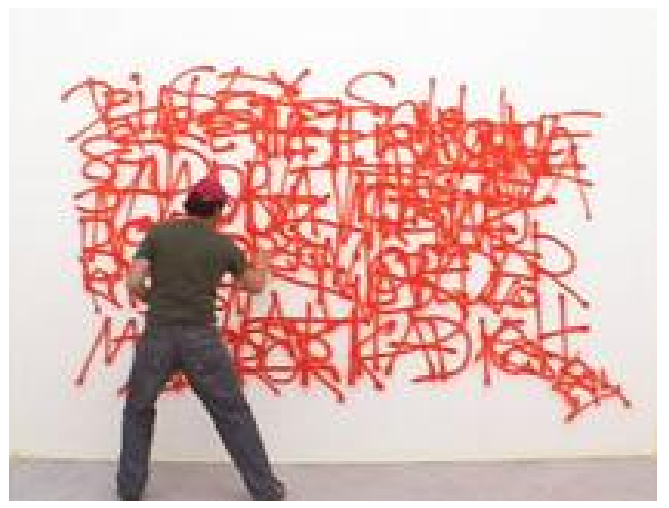

Figura 4. Momento de la performance Viena says... perteneciente a la serie The city says... realizada por Nasan Tur, en el año 2009.

\section{Segundo acto. llegibilidad}

Estas frases durante el proceso de realización de la obra se van superponiendo unas a otras en un tiempo muy veloz hasta que poco a poco se tornan una superficie roja ilegible. En la figura no3 podemos observar como todavía podemos leer las consignas mientras que ya a partir de la figura no4 la imagen comienza a ser ilegible. A traves de la repetición y la reiteración podríamos interpretar como la calle se va quedando en silencio. Es el borrado de la palabra, pero no a traves de la sustracción de la materia prima, si no a través precisamente de la adicción.



Figura 5. Momento de la performance Viena says... perteneciente a la serie The city says... realizada por Nasan Tur, en el año 2009.

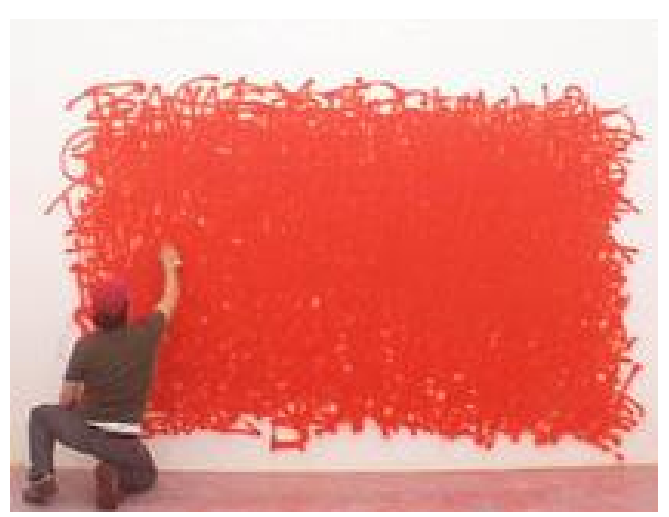

Figura 6. Momento de la performance Viena says... perteneciente a la serie The city says... realizada por Nasan Tur, en el año 2009. 


\section{Tercer acto. Borrado y olvido}

La adicción se vuelve monocromía. A través de la superposición de la palabra se construye el borrado de la identidad. Frente a la imagen omnipresente este borrado de la imagen y de la palabra se convierte en un acto de rebeldía y de posicionamiento que convierte el placer estético en una táctica de cuestionamiento. En este caso, la palabra es borrada por la propia palabra y con ella la acción performativa adquiere una nueva dimensión. A partir de la llamada y de la repetición de estas frases cortas lo que se está haciendo presente es el mutismo de una sociedad precisamente por el exceso de voces.

\section{El borrado por adicción}

Desde Robert Rauschenberg habíamos planteaba el borrado como un proceso principalmente al que se llegaba por medio de la sustracción, ahora deberíamos plantearnos al igual que Nasan Tur, que hay toda una serie de artistas que lo hacen por medio de la adicción.

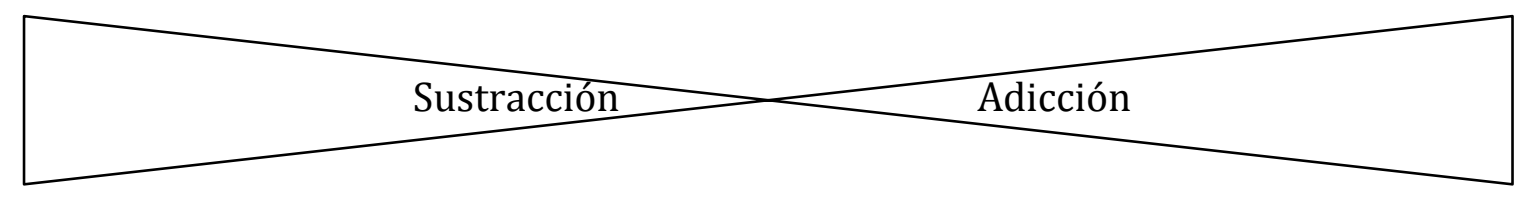

\begin{tabular}{|l|c|}
\hline 1. Borrado por sustracción de materia & 2. Borrado por adicción de materia \\
\hline \multirow{4}{*}{ Robert Rauschenberg } & Mel Bochner \\
\cline { 2 - 2 } & Idris Kan \\
\cline { 2 - 2 } & Dong Yoon Kim \\
\cline { 2 - 2 } & Ozlem Gunyol y Mustafa Kunt \\
\cline { 2 - 2 } & Alexander Gutke \\
\hline
\end{tabular}

Figura 7. Cuadro de adición por borrado. Fuente propia.

Mel Bochner fue de los primeros artistas en los años sesenta en introducir el lenguaje en la plástica visual. Centró su interés en lo que implicaba conceptualmente la pintura más que en lo que visualmente ofrecía. Sus primeros dibujos y fotografías parten de un conjunto de reglas simples que consisten en repeticiones, inversiones, rotaciones o la misma superposición de la imagen.

Idris Kan trabaja en un proceso fotográfico continuo donde en el dibujo y el borrado de imágenes se alternan las superposiciones de capas escritas con los vestigios de lo borrado. Algunas de sus obras en dibujo y en gran formato pueden llegar a las 120.000 líneas de texto lo que las constituye como grandes monocromos negros al estilo de Mark Rothko, Ad Reinhardt, Agnes Martin, Frank Stella o Richard Serra.

Dong Yoon Kim trabaja con fotografías en las que lo que se presentan son imágenes desdibujadas por superposición de acontecimientos. La misma imagen fotográfica presenta diferentes ubicaciones temporales y aunque compositivamente el conjunto es muy armónico los resultados son imágenes tan desdibujadas que son difíciles de identificar.

En Bandera-s, Ozlem Gunyol y Mustafa Kunt construyen una imagen de 246 banderas impresas por superposición unas sobre las otras con una impresora de chorro de tinta hasta optener una sola imagen. Esta imagen luego es transferida a una nueva tela de cuarenta por cuarenta centímetros. El resultado es una obra opaca con restos de pigmentación y donde se anulan todas las identidades nacionales.

Alexander Gutke realiza en el 2007 Subtraktion una obra que consiste en una reflexión sobre la absorción de la luz. El artista imprime en una hoja en blanco el título de una película de terror italiana All the colors of the dark (Todos los colores de la oscuridad) utilizando los colores primarios sustractivos cian, magenta y amarillo para intentar lograr la negrura total. A la ausencia de luz con la que juega el título de la obra llega a través de la adicción de los colores sustractivos. 


\section{Conclusiones.}

Si el borrado se definía como la acción de hacer desaparecer por cualquier medio lo representado, el borrado por adicción de materia lo podríamos definir como aquel proceso en el que artista incorpora la materia en un proceso de superposición y no de ocultamiento que se aleja del tapado y con el que se logra la desaparición de lo representado.

Se trataría de una imagen sin imagen que harían visible lo invisible (Castro Rey, 2012) o en algunos casos de una imagen difusa. En cualquier caso, el lenguaje y la comunicación son aspectos esenciales para las relaciones del ser humano y esta es la parte fundamental de la reflexión de Nasan Tur (Heinrich, 2011). Esta crisis del valor comunicativo que el artista plantea a través del borrado de la palabra como una superficie cubierta de pintura en aerosol es una metáfora de las dificultades que acosan a cualquier forma de comunicación. Rizando el rizo podríamos plantear que la sustracción tiene mucho que ver con la globalización, la normalización de la identidad y el descrédito de lo particular en lo cultural. Mientras que por otro lado, la adicción estaría en relación con el mundo de la ficción, la virtualización del sujeto y el crédito a la ficción particular. Ambas formarían parte de un proceso de normalización y borrado de identidad que encamina al sujeto hacia una nueva cartografía quizá invisible, donde como planteaba Ralph Rugoff para su exposición Invisible: Art about the Unseen 1957-2012, se hace más necesario pensar que mirar.

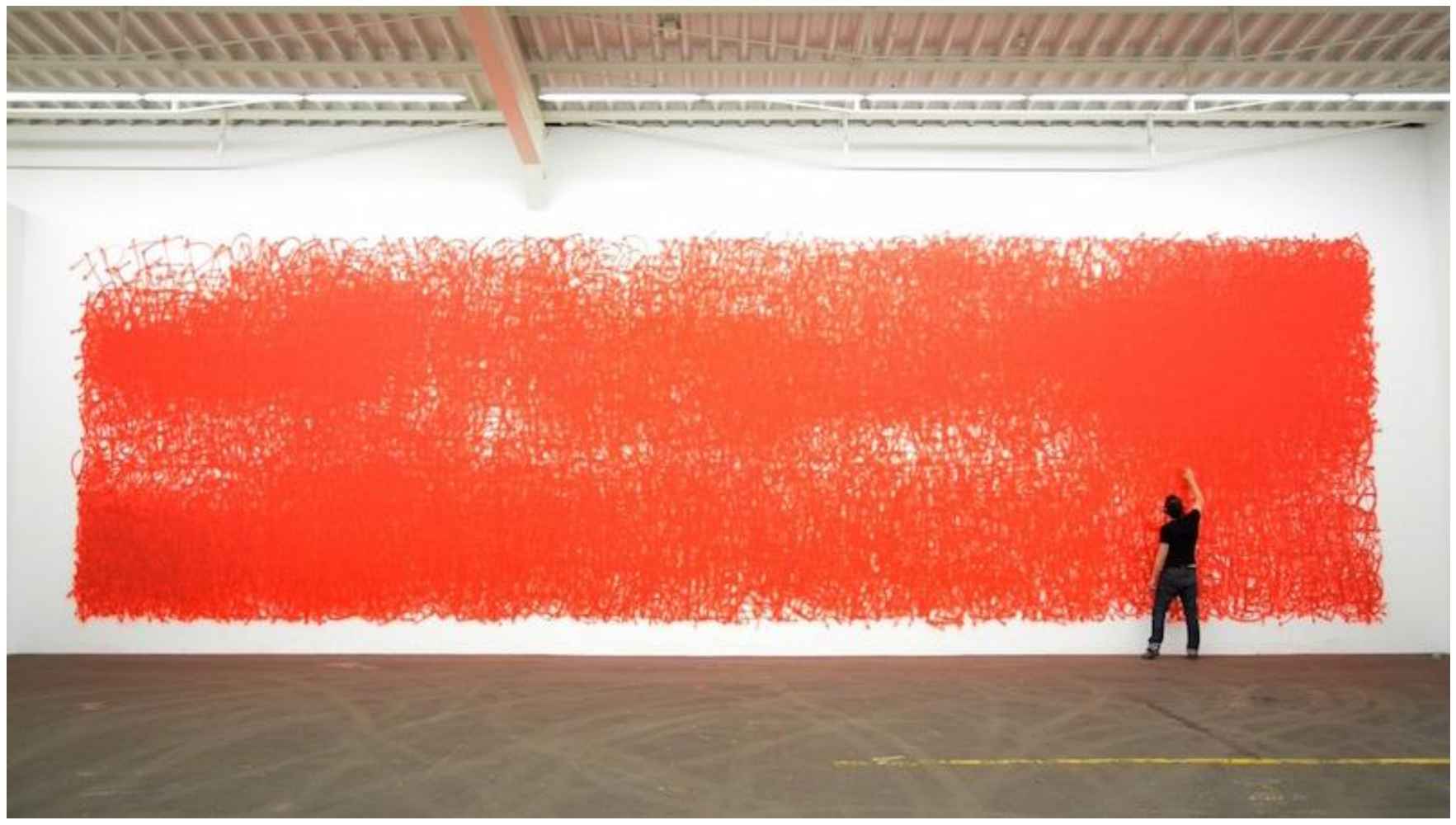

Figura 8. Momento de la performance Berlín says... perteneciente a la serie The city says... realizada por Nasan Tur, en el año 2013.

\section{FUENTES REFERENCIALES.}

Castro Rey, Ignacio. (2012) Imagen sin imagen. FronteraD Revista Digital [Consult. 10-01-2017] http://www.fronterad.com/?q=imagenes-sin-imagen

Heinrich, Barbara. (2011) The Stories behind the Pictures. En Tactics of Invisibility. ISBN 978-3-86560-823-9. Thyssen-Bornemisza Art Contemporary.

Hernández-Navarro. (2006) La so(m)bra de lo real: El arte como vomitorio. Colleció Novatores. ISBN: 84-7822-467-X 
III CONGRESO INTERNACIONAL DE INVESTIGACIÓN EN ARTES VISUALES :: ANIAV $2017:$ : GLOCAL [codificar, mediar, transformar, vivir] http://dx.doi.org/10.4995/ANIAV.2017.5842

Meana Martínez, Juan Carlos. (2011) Poéticas de la negación de lo visual. ISBN: 978-989-8300-14-0

Rugoff, Ralph. (2012) Invisible: Art about the Unseen 1957-2012. ISBN: 978-1-85332-312-6. Hayward Publishing. 